\title{
Does a Hybrid Approach of Agile and Plan-Driven Methods Work Better for IT System Development Projects?
}

\author{
Takeomi Imani*, Masaru Nakano*, and Vittal Anantatmula ${ }^{* *}$ \\ * (Graduate School of System Design and Management, Keio University, Japan) \\ ** (School of Economics, Management, and Project Management, Western Carolina University, USA)
}

\begin{abstract}
With a focus on large-scale IT system development projects in diverse enterprises, this research suggests that a hybrid approach combining agile and plan-driven management methods should fit in a wider context of specific project characteristics. Although the extant research illuminates the advantages of the hybrid approach, very few empirical studies actually suggested that the hybrid approach can improve the likelihood of project success. This research results show that the hybrid approach should be more scalable than the agile method, and that the hybrid approach can provide better cost-benefit ratios compared to the traditional plan-driven method. These quantitative and qualitative findings offer a practical recommendation for the project manager or the project management office to utilize the hybrid approach appropriately.
\end{abstract}

Keywords - Hybrid Approach, Agile, Plan-driven, Survey, Case Study, Project

\section{INTRODUCTION}

It is common in IT system development projects for project managers to deal with both project control issues and fast responses to changes in the project. The challenge in managing system development and IT projects comes from the fact that diverse stakeholders seek both predictability in the project scope and flexibility in the requirements due to uncertain and changing business circumstances. Furthermore, system development is often positioned as a critical subsystem in complex and large-scale hardware product development projects, wherein innovative outcomes are expected expeditiously while phase gates are applied to mitigate risks. In this case, agile methods alone may not be sufficient to produce desired results. Therefore, it is no surprise that research shows a trend of studies focusing a hybrid approach that uses plan-driven and agile-method together in enterprise level IT system development $[1,2,3]$.

However, there are, to the authors' knowledge, very few empirical studies to support that the hybrid approach can improve to the likelihood of project success. To address this knowledge gap, this paper is intended to provide an integrative empirical study of the hybrid approach using statistical data analysis of survey respondents $(n=117)$ and two qualitative case studies in Japan.
The objective of this research is to provide quantitative and qualitative evidence through actual project result data to illustrate that the hybrid approach works better than traditional plan-driven or agile methods for improving specific project success indicators. The hybrid approach has been highlighted as an important area for future research in recent studies on system engineering and project management disciplines $[2,3,4,5]$. The results presented herein contribute to estimating costs and benefits of the hybrid approach compared to those associated with the plan-driven method.

\section{LITERATURE REVIEW}

This section presents a review of the existing literature on plan-driven, agile, and hybrid variants, and defines the scope of the hybrid approach.

\subsection{Plan-driven and Agile Method}

Conventional IT system development organizations selectively utilize two techniques: the plan-driven method in which requirements are defined and base-lined in the initial phase of the project $[6,7]$, and the agile method which is based on iterative, incremental development of the project scope $[8,9,10]$.

The plan-driven methods, also known as the Waterfall method, is an IT system development process that consists of sequential phases that are 
linear. Phases in the plan-driven method typically include requirements analysis, design, implementation, testing and operation. These phases require a sign-off by the project manager to proceed to the subsequent phases. Requirements are baselined before design and implementation and implementation commences using an integrated change control process [7]. Thus, after finalizing the requirements in the initial phase, customer involvement is limited.

With the agile method, on the other hand, re-planning with customers is carried out iteratively even during the execution phase. Although highlevel requirements can be collected early in the project, team should repeatedly prioritize detailed requirements. Agile methodologies include more than six frameworks and practices $[11,12,13,14]$. The most popular variants are Scrum [9], Extreme Programming [15], Crystal [16], Dynamic Systems Development Method [16], Lean software development [17] and Feature Driven Development [18]. The Agile Manifesto [8] consists of four value statements:

- Individuals and interactions over processes and tools

- Working software over comprehensive documentation

- Customer collaboration over contract negotiation

- Responding to change over following a plan

Two of the main features of the agile method are iterative scope definition and development, and incremental delivery $[1,19,20]$. The purpose of agile project management is to deliver reliable and innovative products within the cost and schedule constraints and, to mitigate risks proactively by managing the uncertainties inherent in the iterative process [19]. The agile project team must cope with rapid changes in project plan and active involvement of customers [21]. Project members should be able to improve productivity through the iterative incremental process and the active involvement of key customer members in the process [5]. The agile approach should be suitable for small projects and not for large-scale projects, but less for large-scale projects. The recommended number of team members is between five and nine [22] to be selfmanaged, and it might be not feasible to create the self-managed team in large-scale projects.

Although there are a few empirical studies to support the conclusion that the agile method can improve the likelihood of project success [5], our preliminary study suggested that agile development has been applied in the project situations where novelty on market, system complexity and likelihood on large-scale rework (rate of changes [1]) are all

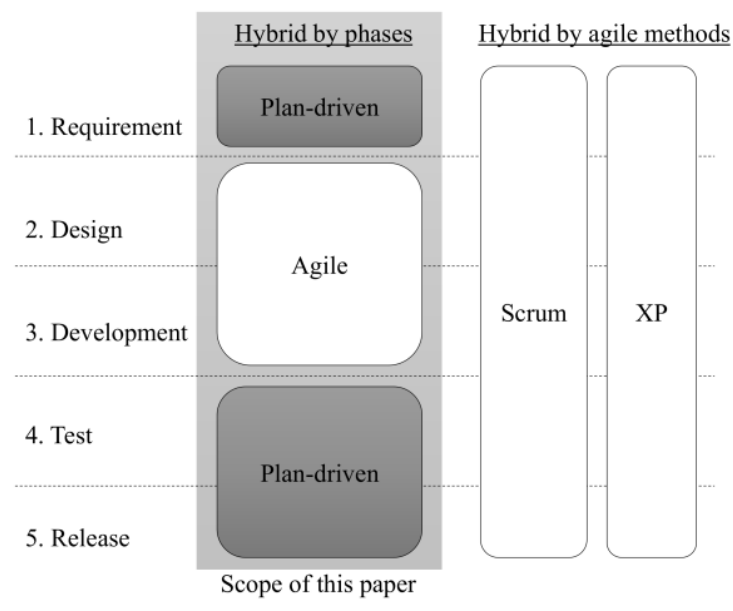

Fig 1. Hybrid approaches

relatively higher [23]. However, the contribution on the cost-benefits would have been very marginal [5, 23]. This paper will compare project size, rate of changes, and cost-benefits of hybrid approach, agile method and plan-driven method.

\subsection{Hybrid Approach}

Recent research suggests an increasing tendency to use hybrid approach for enterprise level projects $[2,3,4,5]$. Consequently, practitioners are faced with three options: plan-driven, agile methods and hybrid approaches [2, 3, 24]. For example, in the field of product development with a high level of novelty, flexible project management methods along with concurrent engineering, and spiral models with prototypes are often considered [25].

The literature review revealed two types of hybrid approach. The first approach is to use both traditional plan-driven and agile variants, depending on the project phase $[1,3,4,5,26]$; we denote this as "Hybrid by phases." The second alternative involves utilizing mixed methods, via Scrum or XP for example, or using a plan-driven estimation tool in an agile development $[27,28,29,30]$. We refer to this as "Hybrid by methods."

Additionally, the hybrid approach can be applied to both IT and non-IT projects. The hybrid approach would be effective in a large system development project where organizational and contractual issues would hinder the iterative development process inherent to agile method [3]. On the other hand, the hybrid approach in a stage-gate model context is often used in hardware product development projects undertaken by small companies [2]. Due to the increasing number of practitioners' articles [3, $31,32]$, this paper will focus on "Hybrid by phases" (Fig 1) for IT system development projects.

Although we could only identify few em- 
pirical studies which support the idea that hybrid approaches can improve the likelihood of project success, we have proposed an integrated decisionmaking flow with 13 input parameters for project managers to comprehensively properly plan and execute such an approach [33]. Through the literature review, our decision tree suggests that the hybrid approach can be applicable in large-scale projects with higher requirement uncertainties. For our empirical study in this paper, it is hypothesized that:

(H1) The hybrid approach can be scalable for projects with high levels of requirement uncertainties.

(H2) The hybrid approach can improve project success rates.

\section{STATISTICAL DATA ANALYSIS}

This section documents our data collection methods and the statistical data analysis results in order to evaluate the two hypotheses stated above.

\subsection{Data Collection}

To investigate properties of projects that use hybrid approaches, we designed an online questionnaire in order to collect data from practitioners; specifically, project managers and project team members in Japan. The questionnaire was distributed to potential respondents between March and June in 2015; several project management and agile development communities were targeted, as well as the authors' professional networks. Similar approaches to data collection have been utilized in previous studies into agile methods [5, 34]. The questionnaire has several sections with 70 questions in total in order to enable integrative analysis: respondent attributes (demographics), project attributes, project characteristics, project results, and project management methods. The project characteristics, actual results, and project management methods were evaluated with ordinal 5-point Likert scales. The questionnaire and descriptive analysis are provided in Appendix A. In a previous study [23], the authors demonstrated the relationships between project success factors and agile methods with the same questionnaire; however, this paper focuses on the hybrid approach.

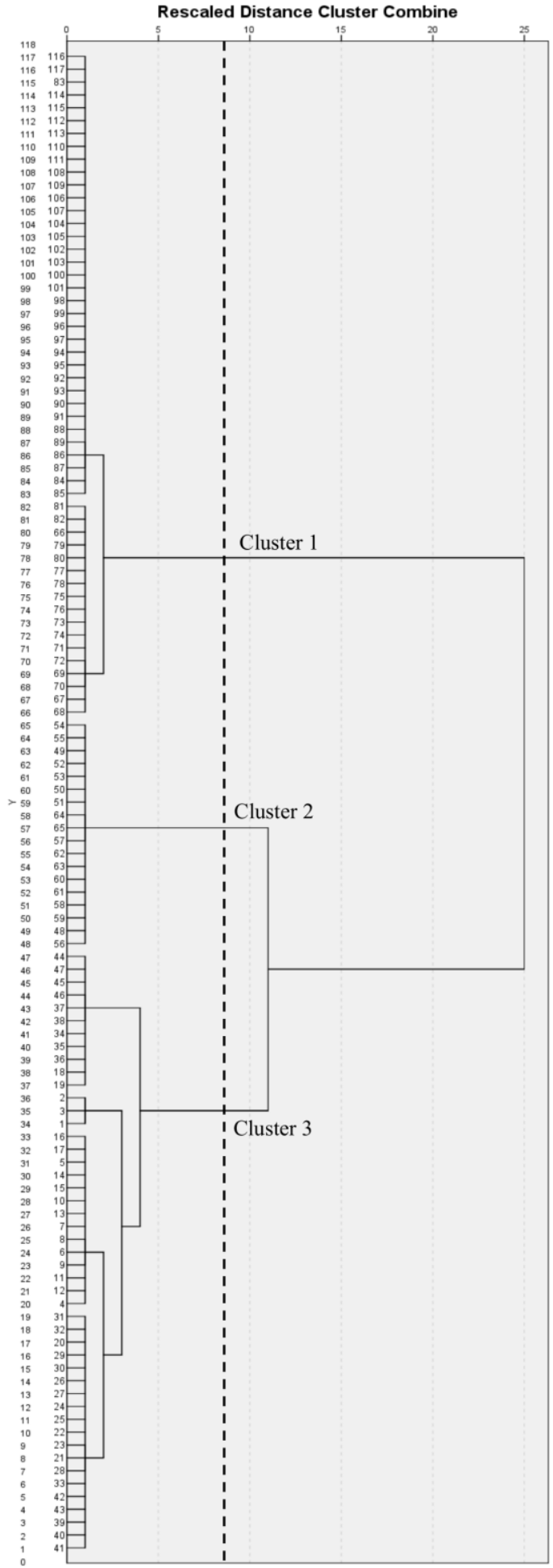

Fig 2. Dendrogram using Ward linkage (Dashed line is to determine the number of clusters) 

ISSN : 2248-9622, Vol. 7, Issue 3, ( Part -4) March 2017, pp.39-46

Table 1: Methods and project attributes: cluster and ANOVA analysis

\begin{tabular}{|c|c|c|c|c|c|c|c|c|c|c|}
\hline \multirow[t]{3}{*}{ Cluster } & \multirow[t]{3}{*}{$\mathrm{N}$} & \multicolumn{9}{|c|}{ Means and ANOVA } \\
\hline & & \multicolumn{2}{|l|}{ Methods } & \multicolumn{3}{|l|}{ Attributes } & \multicolumn{4}{|c|}{ Methods in detail } \\
\hline & & $\begin{array}{c}\text { Agile } \\
\text { method rates } \\
\left(\mathrm{Q} 15 \_12\right) \\
\end{array}$ & $\begin{array}{c}\text { Plan-driven } \\
\text { method rates } \\
\text { (Q15_11) }\end{array}$ & $\begin{array}{l}\text { Project } \\
\text { Size } \\
\text { (Q8) } \\
\end{array}$ & $\begin{array}{c}\text { Project } \\
\text { Duration } \\
\text { (Q9) } \\
\end{array}$ & $\begin{array}{c}\text { Rate of } \\
\text { requirement } \\
\text { changes } \\
\text { (Q10_9) }\end{array}$ & $\begin{array}{c}\text { Scoping in } \\
\text { initial phase } \\
\text { (Q15_1) }\end{array}$ & $\begin{array}{c}\text { Scheduling } \\
\text { in single } \\
\text { path } \\
\text { (Q15_2) }\end{array}$ & $\begin{array}{l}\text { Phase gate } \\
\text { review with } \\
\text { document } \\
\left(\mathrm{Q} 15 \_3\right) \\
\end{array}$ & $\begin{array}{c}\text { Phase gate review } \\
\text { with working } \\
\text { system } \\
\text { (Q15_8) }\end{array}$ \\
\hline 1 (Hybrid) & 47 & 2.77 & 3.64 & 1.64 & 3.45 & 3.47 & 3.76 & 3.26 & 3.38 & 3.21 \\
\hline 2 (Agile) & 18 & 4.33 & 1.50 & 1.56 & 3.67 & 3.89 & 3.44 & 2.28 & 2.72 & 3.83 \\
\hline 3 (Plan-driven) & 52 & 1.00 & 4.67 & 2.21 & 3.73 & 3.10 & 4.10 & 4.44 & 3.92 & 2.87 \\
\hline All clusters & 117 & 2.22 & 3.77 & 1.88 & 3.60 & 3.37 & 3.86 & 3.63 & 3.52 & 3.15 \\
\hline $\mathrm{F}$ & & 119.62 & 186.79 & 4.61 & 0.89 & 2.85 & 2.55 & 26.40 & 6.43 & 3.53 \\
\hline $\mathrm{p}(\mathrm{F})$ & & 0.000 & 0.000 & 0.012 & 0.413 & 0.062 & 0.083 & 0.000 & 0.002 & 0.032 \\
\hline
\end{tabular}

We collected survey responses from 117 individuals, excluding 27 responses due to missing values. Respondents represented companies which were large (more than 10,000 employees, 27\%), medium (500-10,000 employees, 40\%), and small (less than 500 employees, $38 \%$ ). In total $50 \%$ of the projects involved more than 20 team members, while the duration of $50 \%$ of projects exceeded 1 year. However, $70 \%$ of respondents were project managers and $70 \%$ of them had over 10 years' experience in project management.

\subsection{Statistical Analysis Result}

Our hierarchical cluster analysis and oneway analysis of variance (ANOVA) analysis indicated a cluster of hybrid approach which has responses from both agile and plan-driven methods (Fig 2 and Table 1). Using the rates of the agile and plandriven methods (Q15_1 and Q15_2 in Appendix A), the cluster analysis with Ward methods suggests three cluster; a chi-squared test rejects the null hypothesis that the data are independent $\left(\chi^{2}=17.28, d f=2\right.$, $p<.001)$.

As is evident shown in Table 1, cluster 1 can be identified as hybrid approach since agile (Q15_12) and plan-driven (Q15_11) methods both feature to a relatively high extent $(p<.000)$. In addition, the hybrid approach (cluster 1) were used in the projects where the rate of requirement changes (Q10_9) was higher as compared to the pure plandriven methods (cluster 3), and where the project size of projects (Q8) was lager as compared to the pure agile method (cluster 2). These results support the first hypothesis (H1) in section II that the hybrid approach can be scalable for projects with high levels of requirement uncertainties.

In detail, cluster 1 (hybrid) used the plandriven methods more than cluster 2 (pure agile) and leveraged agile method more than cluster 3 (pure plan-driven). As shown in Table 1, those results can be found in three plan-driven methods (scoping: Q15_1, scheduling: Q15_2, and gate review by document: Q15_3) and one agile method (gate review by the working system: Q15_8). In other responses about plan-driven or agile methods (Q15_\# in the Appendix A), significant differences were not found among three clusters.

Furthermore, cluster 1 (hybrid) has a larger average rates of project success on cost (within budget, Q11_1 in Table 2). Cluster 2 (agile) has largest average rates on project quality (Q11_1) and project sponsor identification of the success (Q11_4). Cluster 3 (plan-driven) has a marginally larger average rates of project success on duration (on time, Q11_3). This finding can be extracted through a descriptive analysis in Table 2. Although one-way ANOVA F-test cannot provide support in a statistical sense, in descriptive terms Table 2 results marginally support the second hypothesis (H2) described in section II that the hybrid approach can improve project success rates, specifically in terms of cost.

Table 2: Project success rates for each cluster with descriptive analysis

\begin{tabular}{llrrrc}
\hline Cluster & \multicolumn{5}{c}{ Means and Standard Deviation } \\
\cline { 3 - 6 } & & Quality & Cost & Delivery & $\begin{array}{c}\text { Sponsor } \\
\text { satisfaction } \\
(\text { Q11_4) }\end{array}$ \\
\hline 1(Hybrid) & mean & 4.04 & $\mathbf{3 . 8 1}$ & 3.96 & 4.19 \\
& s.d & .908 & 1.262 & 3.96 & .947 \\
2 (Agile) & mean & $\mathbf{4 . 3 3}$ & 3.78 & 3.78 & $\mathbf{4 . 3 9}$ \\
& s.d & .594 & 1.114 & 3.78 & .608 \\
3 (Plan-driven) & mean & 3.98 & 3.52 & $\mathbf{4 . 0 0}$ & 4.15 \\
& s.d & 1.229 & 1.421 & 4.00 & 1.161 \\
All clusters & mean & 4.06 & 3.68 & 3.95 & 4.21 \\
& s.d & 1.028 & 1.312 & 3.95 & 1.005 \\
\hline
\end{tabular}




\section{CASE STUDIES}

This section provides qualitative evidence through case studies that used hybrid approaches successfully with specific project properties, and further evaluates the two hypotheses in section II.

\subsection{Data Collection}

We selected two IT system development projects from two different business organizations that used hybrid approaches. Data were collected through interviews; their authenticity was then validated by accessing publicly available information such as conference proceedings and articles [3, 35]. Two project managers involved in projects that employed the hybrid approach were interviewed to collect information for case studies. Main interview questions aimed to understand (1) needs of key stakeholders, (2) project characteristics such as size and duration, (3) project management approach and its contextual background, (4) issues and measures, and (5) final results and lessons learned from the project. Interview scripts were sent to the project managers ahead of the interviews, followed by 90 minute face-to-face interviews. These interviews were held between March and July 2016. These interviews were held between March and July 2016. The recorded conversations were converted to MS Word documents and sent to interviewees for corroboration.

\subsection{Project Alpha}

The objective of this large-scale (multiple teams) global procurement system integration project in a leading IT technology company. The objective of that project is to deploy the using a common procurement process and across interfaces with major customers in six countries. Although the highest priority of the stakeholders was to complete the project within 9 months, approximately $50 \%$ of the requirements have not been well defined. The project exhibits technical risk in terms of data interfaces and cross-country design alignment which could result in escalated costs to implement the system.

To deal with uncertainties and mitigate risks, the project team adopted a hybrid approach of plan-driven and agile methods. The initial phase used the plan-driven method with 2.5 months included for defining requirements and high-level design. The core project team documented detailed requirements for efficient communication with other
Table 3: Summary of case study results

\begin{tabular}{|c|c|c|}
\hline & Project alpha & Project Beta \\
\hline Scope & $\begin{array}{l}\text { Procurement system } \\
\text { integration project and } \\
\text { global roll-out }\end{array}$ & $\begin{array}{l}\text { Web-based human } \\
\text { resource management } \\
\text { system. }\end{array}$ \\
\hline Size & Large (6 team) & Small (single team) \\
\hline $\begin{array}{l}\text { Requirement } \\
\text { uncertainty }\end{array}$ & $\begin{array}{l}\text { High } \\
\text { (50\% of all requirements) }\end{array}$ & $\begin{array}{l}\text { Middle } \\
\text { ( } 20 \% \text { of all requirements) }\end{array}$ \\
\hline Agile method & $\begin{array}{l}\text { Scrum method in the } \\
\text { development phase }\end{array}$ & $\begin{array}{l}\text { Three-week times three } \\
\text { cycle of the iteration } \\
\text { development with } 20 \% \text { cap } \\
\text { of changes }\end{array}$ \\
\hline $\begin{array}{l}\text { Plan driven } \\
\text { method }\end{array}$ & $\begin{array}{l}\text { Documented detailed } \\
\text { requirements for efficient } \\
\text { communication with other } \\
\text { teams. } \\
\text { Risk response planning } \\
\text { with the defined } \\
\text { architecture document }\end{array}$ & $\begin{array}{l}\text { In the initial phase and } \\
\text { high-level design phase, } \\
\text { quality management } \\
\text { process adopted. } \\
\text { The test phase has } \\
\text { integration and acceptance } \\
\text { test. }\end{array}$ \\
\hline Results & $\begin{array}{l}\text { Successfully completed on } \\
\text { time }\end{array}$ & $\begin{array}{l}\text { Successfully completed on } \\
\text { time }\end{array}$ \\
\hline $\begin{array}{l}\text { Cost reduction } \\
\text { rates as } \\
\text { compared with } \\
\text { plan-driven }\end{array}$ & $\begin{array}{l}>15 \% \\
\text { (estimated) }\end{array}$ & $\begin{array}{l}\sim 8 \% \\
\text { (measured) }\end{array}$ \\
\hline
\end{tabular}

teams. The project leader in the core project team stated that "the initial phase was important to officially reach agreement with all the teams about the documented architecture and review." In the development phase, the core project team used the Scrum method to respond to changes efficiently. Iteration developments delivered not only functional requirements but also non-functional requirements that are usually managed by the plan-driven method. The development phase also incorporated plan-driven practices such as risk response planning along with multi-national stakeholders. The project team tried to manage the coordination with several teams with a defined architecture document and this plandriven-like document contributed to effective iterative development and the success of the project. As the project manager revealed to us: "Using Scrum with a light process of change control, we roughly estimated more than 15\% cost (work effort) reduction. But if we did not agree with the architecture document in the initial phase, we could not have identified the source (problem) when they happened and it would have caused a delay with the release. The planning approach to avoid those risks was one of the success factors of this project."

As summarized in Table 3, this case would support the two hypotheses (H1) and (H2) in section II. In a large-scale project alpha that used a hybrid approach with a plan-driven initial phase and a de- 
fined architectural document, the project scope was a large-scale (multiple teams) global system integration project. Although approximately $50 \%$ of the requirements have not been well defined, the project was successfully completed with the Scrum method in the development phase to reduce change costs.

\subsection{Project Beta}

The objective of this small-scale (single team) project in a power supply company was to implement a web-based human resource management system. This project required high-level security and rigid authorization control. Further, the system interface is needed with other enterprise systems. Previously, the legacy system was used for many years, and the specification document of the legacy system had not been updated for its migration to the web-based application.

The project management team decided to use a hybrid approach to deal with the uncertainty associated with requirements and to ensure highlevel quality assurance. In the initial phase and highlevel design phase, the plan-driven method was adopted. With uncertainty cone analysis, the cap of the cost increase was estimated to be $20 \%$ of the total cost. In the detailed design and development phase, the agile method with three cycles of iterative development (Scrum) was used. The duration of each iteration was 3 weeks. The test phase was executed as a plan-driven method. Although 20 changes had to be incorporated, the project finished on-time and achieved about an $8 \%$ cost-reduction as compared with the plan-driven approach in all the phases. The project manager of the development vendor stated: "In the plan-driven method, the cost would increase by $50 \%$ because the rework had to be done as phase-2 after the first release. In this hybrid approach, such rework did not happen, since the customer was requested to attend meetings after completion of each iteration to review the working of the system.... the customer's satisfaction level was higher in using the hybrid approach than the plandriven approach. The users can interact with the system easily even without the detailed instruction manual since the detail development was done after listening to user opinions."

As summarized in Table 3, this case further supports the two hypothesis $(\mathrm{H} 1)$ and $(\mathrm{H} 2)$ stated in section II. In this small project with a high level of requirement uncertainty, the hybrid approach can be used. Using agile iterative development and the plan-driven test phase, the project was successfully completed on-time with a measured cost-reduction as compared with the plan-driven approach.

\section{DISCUSSION}

The objective of this research is to provide quantitative and qualitative integrative evidence that hybrid approaches work better than traditional plandriven method or agile method. First, both survey data and the case studies supported the hypothesis that the hybrid approach can be scalable on project size (number of teams) for projects with high levels of requirement uncertainties (H1 in section II). Existing literature has asserted that pure agile methods are more common in small single team consisting of 6-10 members [19]. Our case studies were substantively heterogeneous in scale and scope, yet the hybrid approach worked well in both (Table 3). Second, both survey data and the case studies support the hypothesis that the hybrid approach can improve project success rates (H2 described in section II), specifically with respect to cost. Existing literature has posited that the pure agile approach tends to only offer marginal cost improvements [5, 23]. Our case studies showed that the hybrid approach is expected to provide bigger cost benefit as compared with the plan-driven method in largerscale IT system development projects (Table 3).

These quantitative and qualitative findings can form the basis of practical recommendations for project managers or project management offices (PMO) to appropriately utilize hybrid approaches. In IT system projects with higher requirement uncertainties and larger numbers of teams, the hybrid approach combining agile development and plandriven requirement definition and tests would increase the likelihood of improving the cost-benefit ratio by possibly $8-15 \%$ as compared with the pure plan-driven method.

\section{CONCLUSION}

This paper presented an empirical study of the usage and benefits of hybrid approaches combining the agile and traditional plan-driven methods. Our statistical analysis and case studies provided quantitative and qualitative integrative evidence that hybrid approaches work better in larger-scale project contexts with higher levels of requirement uncertain- 
ty. Further, the hybrid approach increases the likelihood of improving the cost-benefit ratio, compared to purely plan-driven methods.

Although these findings may provide practical insights to appropriately utilize hybrid approaches, our empirical study has limitations in that the results may not necessarily generalize beyond our survey sample and case-study interviewees. Our past research indicated that the pure agile method could be used in low-criticality projects and the agile team would need higher skill on agile iterative developments [23]. Further empirical research is certainly warranted to explore and understand the contexts and criteria against which these different methods are appropriate.

\section{REFERENCES}

[1] Boehm, B. and Turner, R.: "Balancing agility and discipline: Evaluating and integrating agile and plan-driven methods", Proceedings of the 26th international Conference on Software Engineering, pp. 718-719, IEEE Computer Society, 2004

[2] Conforto, E. C. and Amaral, D. C.: "Agile project management and stage-gate model-A hybrid framework for technology-based companies, " Journal of Engineering and Technology Management, 2016.

[3] Hanabusa, S.: Hybrid Agile Execution, Ric Telecom, 2013. (In Japanese)

[4] Hayata, T. and Han, J.: "A hybrid model for IT project with scrum, " Proc. IEEE Conf., pp. 285-290, 2011.

[5] Serrador, P. and Pinto, J. K.: "Does Agile work? - A quantitative analysis of agile project success, " International Journal of Project Management, Vol. 33, No. 5, pp. 1040-1051, 2015.

[6] Royce, W. W.: "Managing the development of large software systems, " proceedings of IEEE WESCON, Vol. 26, No. 8, pp. 1-9, 1970.

[7] Project Management Institute: A guide to the project management body of knowledge (PMBOK ${ }^{\circledR}$ guide), Fourth, Newtown Square, PA: Author, 2008.

[8] Beck, K., Beedle, M., Van Bennekum, A., Cockburn, A., Cunningham, W., Fowler, M., Grenning, J., Highsmith, J., Hunt, A. and Jeffries, R.: "Manifesto for agile software development, " http://agilemanifesto.org, 2001.

[9] Schwaber, K. and Beedle, M.: Agile Software Development with Scrum, Prentice Hall, Upper Saddle River, 2001.

[10] Turk, D., France, R. and Rumpe, B.: "Limitations of agile software processes, " arXiv preprint arXiv:1409.6600, 2014.

[11] Dybå, T. and Dingsøyr, T.: "Empirical studies of agile software development: A systematic review, " Information and software technology, Vol. 50, No. 9, pp. 833-859, 2008.

[12] Project Management Institute: "PMI-ACP ${ }^{\circledR}$ Practitioner FAQs, ",

http://www.pmi.org/ /media/Files/PDF/Certification/PMIACP_Practitioner_FAQ_March2012.ashx, 2013.

[13] Glaiel, F., Moulton, A. and Madnick, S.: "Agile project dynamics: A system dynamics investigation of agile software development methods, " Proc. 31st International Conference of the System Dynamics Society, 2013.

[14] Beck, K.: Extreme programming explained: embrace change, Addison-Wesley Professional, 2000

[15] Hiwarkar, K., Doshi, A., Chinta, R. and R, Manjula.:
"Comparative Analysis of Agile Software Development Methodologies-A Review, " Journal of Engineering Research and Applications, Vol. 6, No. 3, pp. 80-85, 2016.

[16] Cockburn, A.: Crystal clear: a human-powered methodology for small teams, Pearson Education, 2004

[17] Poppendieck, M. and Poppendieck, T.: Lean software development: an agile toolkit, Addison-Wesley Professional, 2003.

[18] Palmer, S. R. and Felsing, M.: A practical guide to featuredriven development, Pearson Education, 2001.

[19] Highsmith, J.: Agile project management: creating innovative products, Pearson Education, 2009.

[20] Dyba, T. and Dingsoyr, T.: "Agile project management: from self-managing teams to large-scale development, "Proc. IEEE Conf., Vol. 2, pp. 945-946, 2015.

[21] Conforto, E. C., Amaral, D. C., da Silva, S. L.,Di Felippo, A. and Kamikawachi, D. S. L.: "The agility construct on project management theory, " International Journal of Project Management, Vol. 34, No. 4, pp. 660-674, 2016.

[22] Sutherland, J. and Sutherland, J.: Scrum: the art of doing twice the work in half the time, Crown Business, 2014.

[23] Imani, T. and Nakano, M.: "Agile Development Method: Where Is It Better Fit, and How Is It Related to a Project Success? " Japan Society for Information and Management, in press, 2017. (In Japanese)

[24] Špundak, M.: "Mixed Agile/Traditional Project Management Methodology-Reality or Illusion? " Procedia-Social and Behavioral Sciences, Vol. 119, pp. 939-948, 2014.

[25] Akkermans, H. and van Oorschot, K. E.: "Pilot Error? Managerial Decision Biases as Explanation for Disruptions in Aircraft Development, " Project Management Journal, Vol. 47, No. 2, pp. 79-102, 2016.

[26] Vinekar, V., Slinkman, C. W. and Nerur, S.: "Can agile and traditional systems development approaches coexist? An ambidextrous view, " Information Systems Management, Vol. 23, No. 3, pp. 31-42, 2006.

[27] Nisa, S. U. and Qureshi, M. R. J.: "Empirical Estimation of Hybrid Model: A Controlled Case Study, " International Journal of Information Technology and Computer Science (IJITCS), Vol. 4, No. 8, pp. 43, 2012.

[28] Mushtaq, Z. and Qureshi, M. R. J.: "Novel Hybrid Model: Integrating Scrum and XP, "International Journal of Information Technology and Computer Science (IJITCS), Vol. 4, No. 6, pp. 39, 2012.

[29] Jahr, M.: "A Hybrid Approach to Quantitative Software Project Scheduling Within Agile Frameworks, " Project Management Journal, Vol. 45, No. 3, pp. 35-45, 2014.

[30] Fitzgerald, B.,Hartnett, G. and Conboy, K.: "Customising agile methods to software practices at Intel Shannon, " European Journal of Information Systems, Vol. 15, No. 2, pp. 200-213, 2006.

[31] Leffingwell, D.: Scaling software agility: best practices for large enterprises, Pearson Education, 2007.

[32] Ambler, S. W.: "Agile software development at scale, " Balancing agility and formalism in software engineering, Springer Berlin Heidelberg, 2008.

[33] Imani, T. and Nakano, M.: "Managing Large-Scale IT Projects: A Decision-making Flow Using Plan-driven and Agile Method for a Hybrid Approach, " Journal of the Society of Project Management, Vol. 18, No. 3, pp. 14-19, 2016. (In Japanese)

[34] Chow, T. and Cao, D.: "A survey study of critical success factors in agile software projects, " Journal of Systems and Software, Vol. 81, No. 6, pp. 961-971, 2008.

[35] Manabe, D.: "The Successful Agile Development Project Management Case Which Involves Multiple Countries, " 27th National Conference of The Society of Project Management, pp. 143-147, 2016. (In Japanese) 

ISSN : 2248-9622, Vol. 7, Issue 3, ( Part -4) March 2017, pp.39-46

Appendix A. Questionnaire (The responses of the underlined questions were analyzed in this paper.)

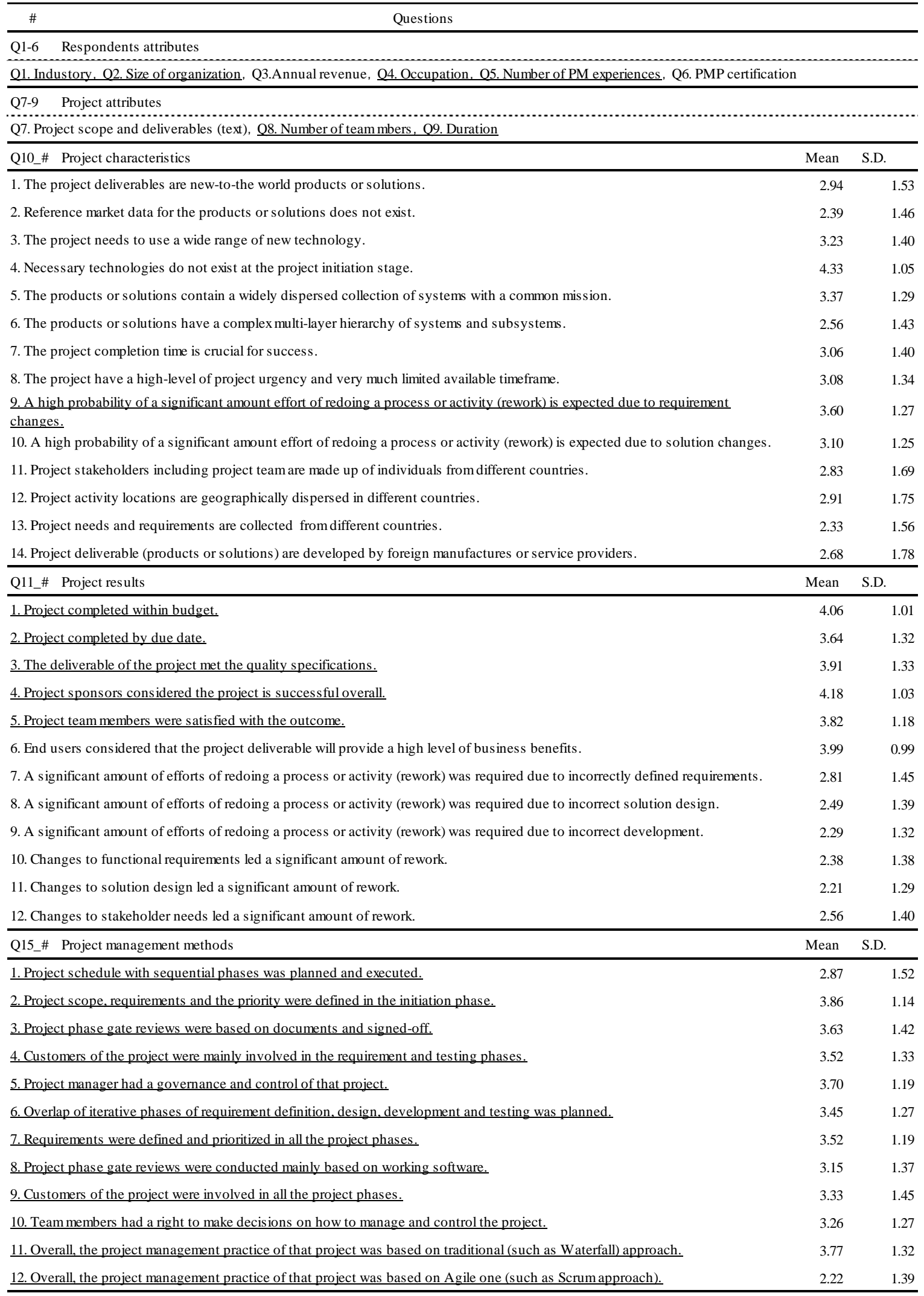

